\title{
Shrubland Restoration
}

\author{
By: Ruben Lopez, Remote Intern Supervised by Walter G. Levernier
}

\section{Introduction}

The shrubland at Fermilab is an area home to many species such as songbirds, insect and a variety of plant life. While it has its inhabitants many native songbirds are decreasing in population and this may be because the area is not suitable for these birds anymore. The three specific birds impacted the most are the yellowbreasted chat, bells vireo, and the willow flycatcher. The area is currently not offering a suitable habitat for these native birds for many reasons.
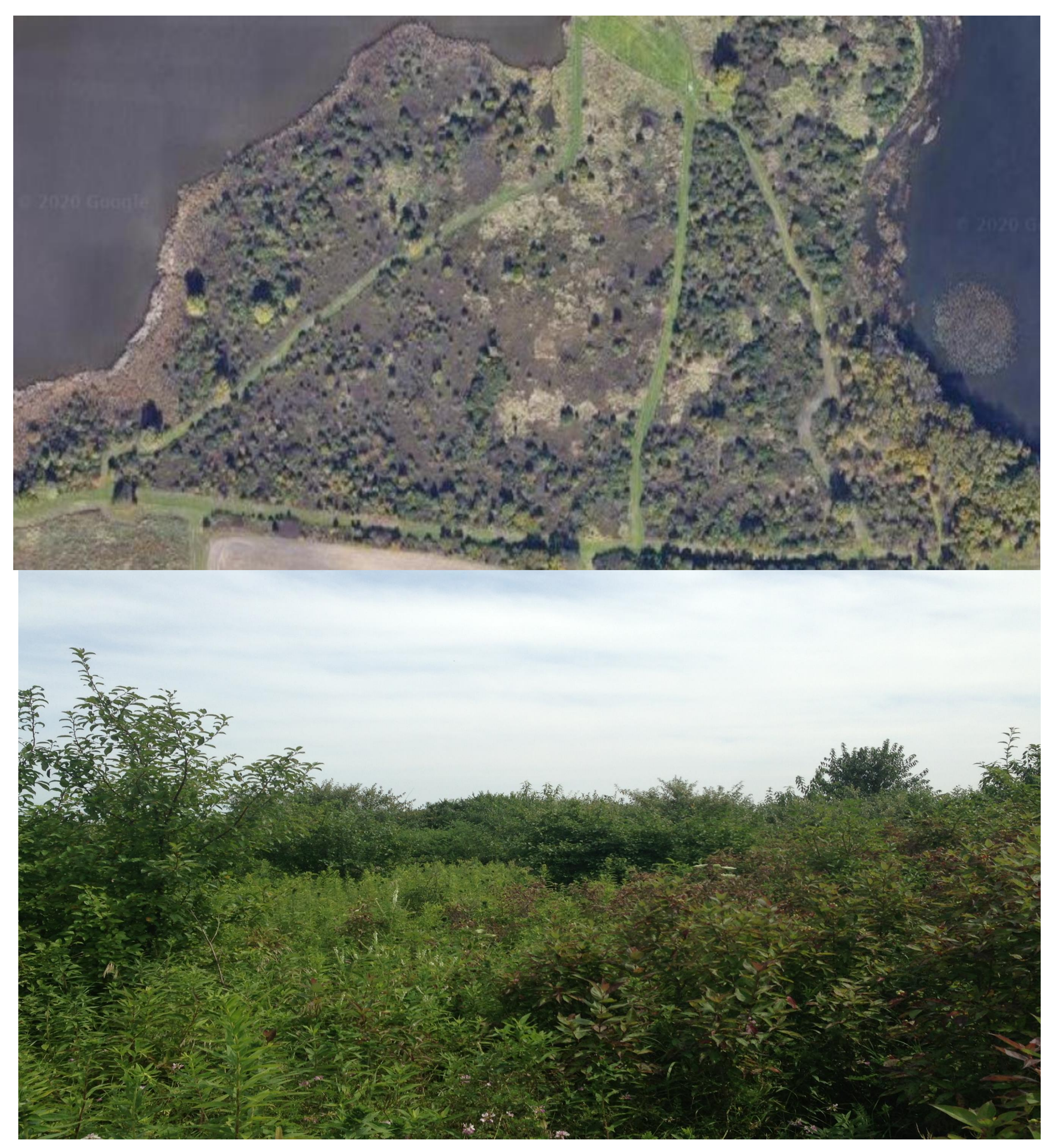

The picture above (on top) shows an aerial view of the sparrow hedge at Fermilab.

The picture below it shows how the shrubland looks when walking through it.

\section{Goals}

- The picture above shows how crowded the shrubs are and why the area may not be suitable for the three birds.

- The main goal, because of this, is to restore and create a sustainable habitat for these native songbirds.

- A secondary goal would be to eliminate all trees from this area and reduce the number of non-native shrubs to less than $5 \%$ coverage.

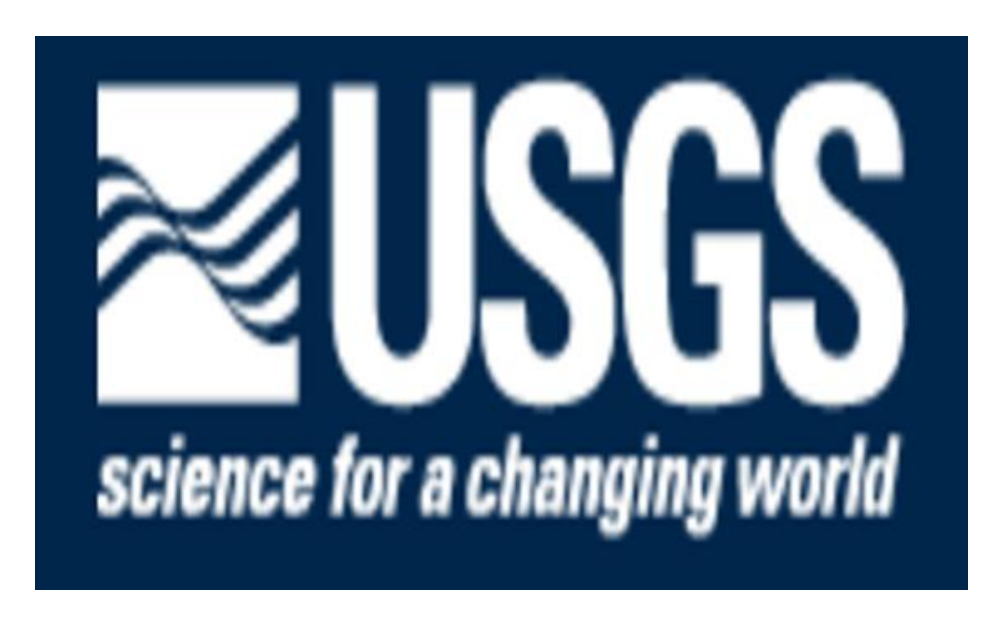

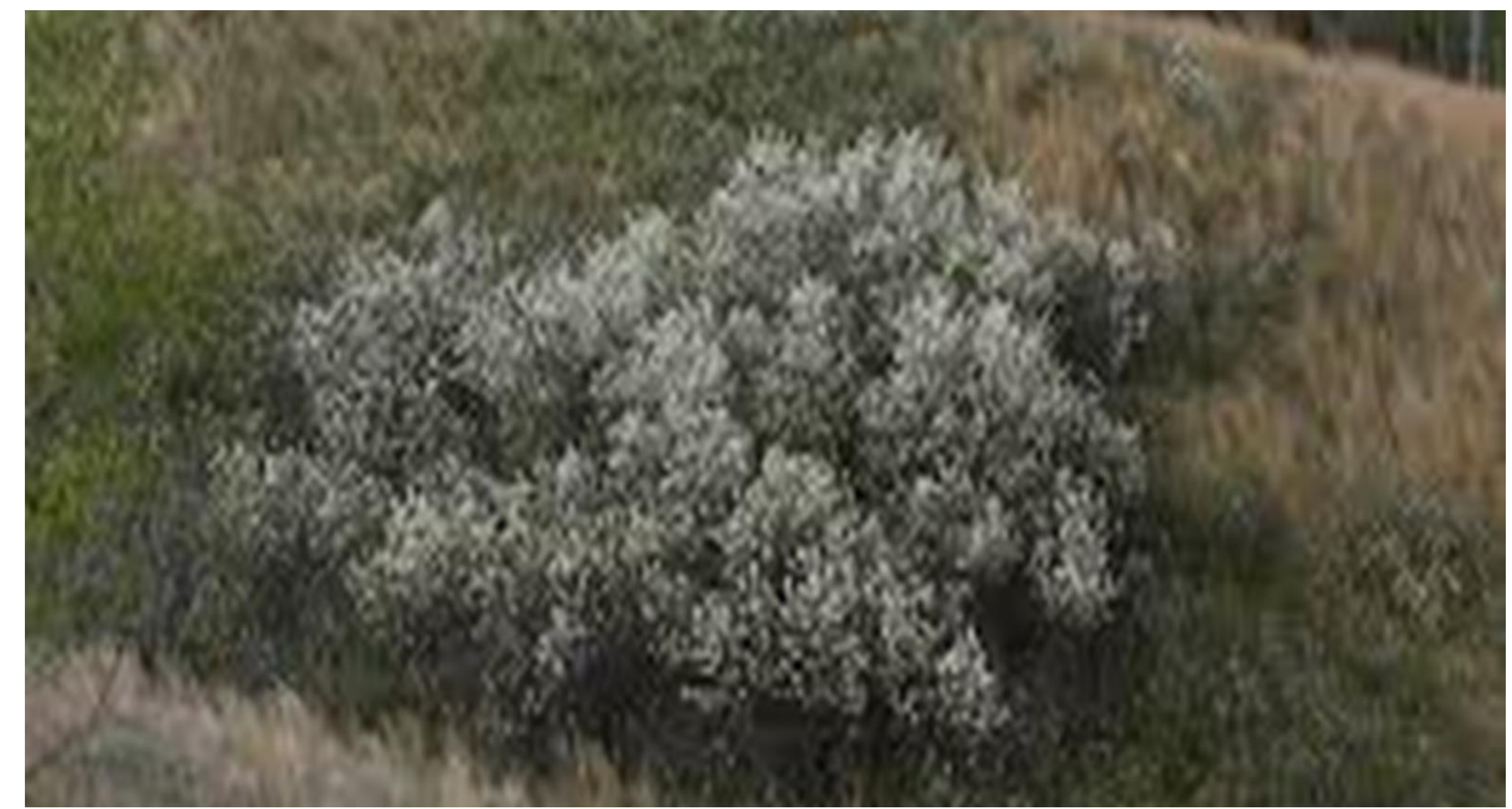

Wildplum is a native shrub that offers fruit and a great habitat for the songbirds. This is very effective

because the fruit attracts insects, and this provides the diet birds desire.

- While changes will be made slowly, the replacement of non-native shrubs with native ones will be a key factor in creating and restoring a habitat for native birds. This will happen around spring before birds migrate to this site and after the vegetation is either burned or mowed. This will allow workers to walk through with tools to cut down or spray (with oil or water-based herbicides) trees, old shrubs with dead branches towards the ground and non-native shrubs. Removing the older shrubs is also necessary because these native songbirds prefer to nest lower to the ground and the shrubs with lower dead branches would not be suitable. Planting new shrubs allow the workers to control the distance between shrubs (which should be about $15 \mathrm{~m}$ to $20 \mathrm{~m}$ in half of the site and in the other half $10 \mathrm{~m}$ to $15 \mathrm{~m}$ ).

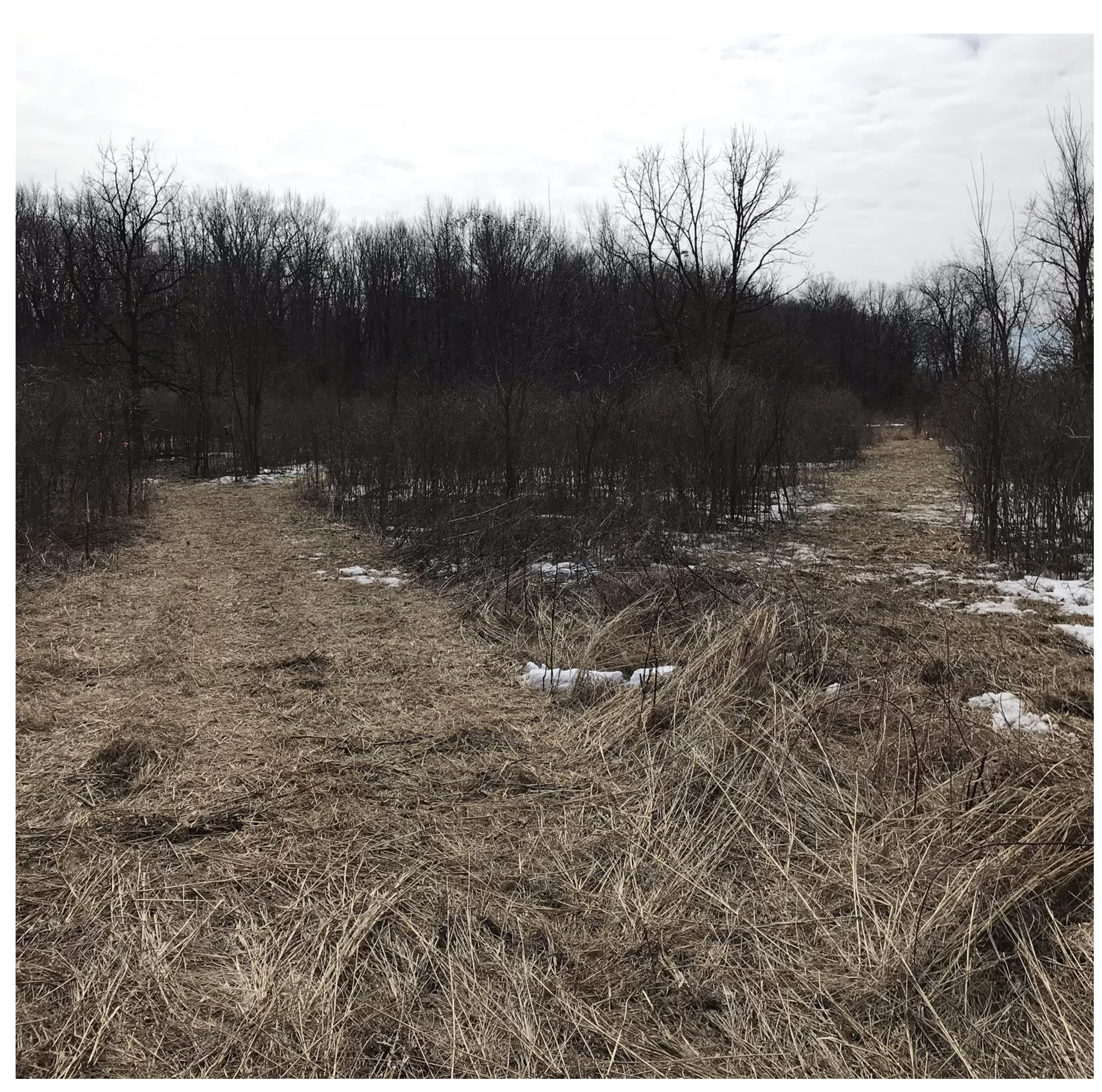

Prescribed fires will eliminate the build up of wildflowers and tall grasses between shrubs from previous years. This will be done around Fall or early spring. Fires should also be done when the proper conditions are met (as in temperature, humidity, wind etc.).

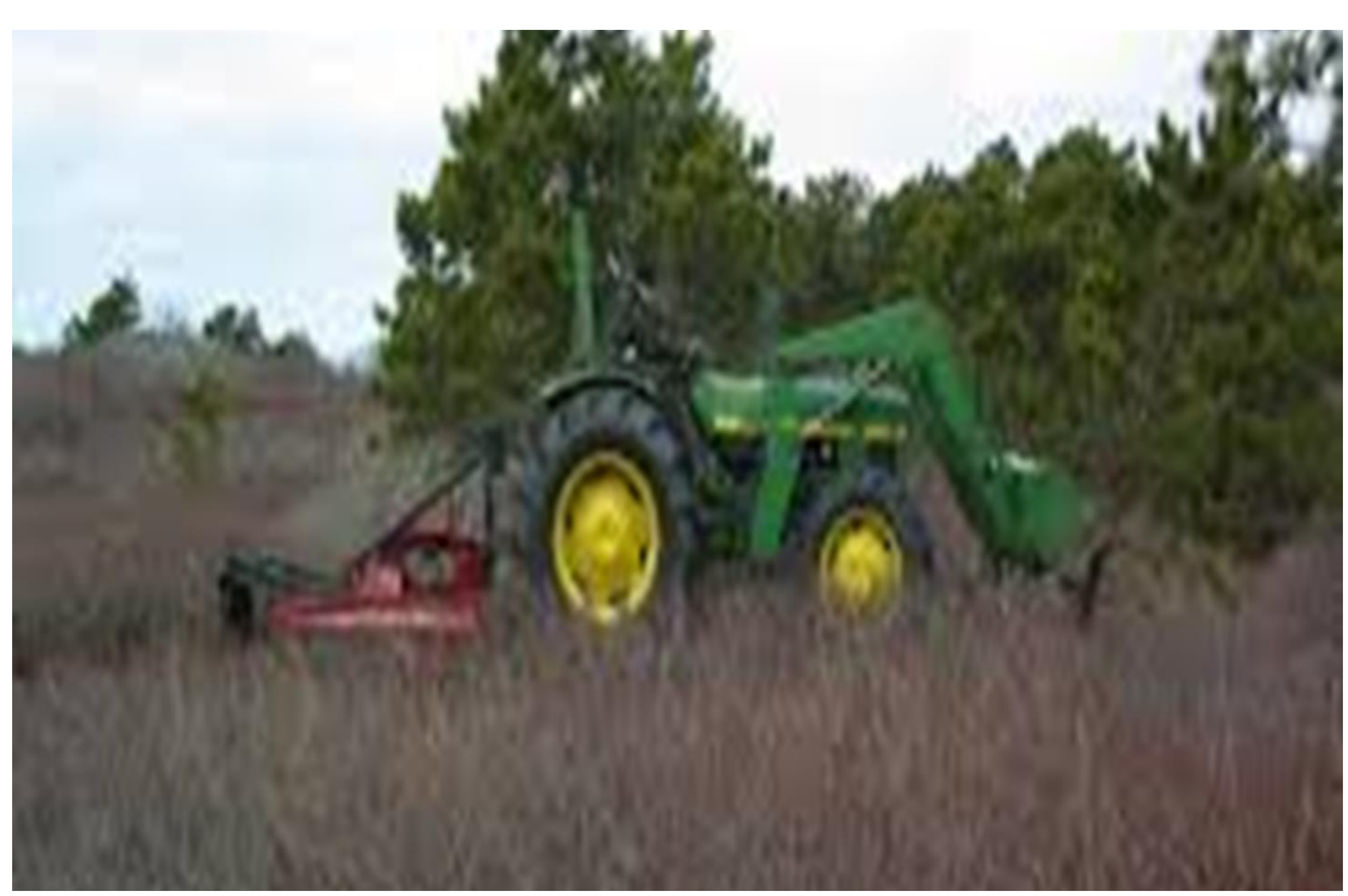

Prescribed mowing is another way to control and manage the vegetation between shrubs. This; however, will be more frequent than the prescribed fires. It should be done every three weeks to prevent overgrowth. This will allow the requirements of a healthy shrubland to be met.

\section{Longevity}

Restoring the area will be done once there is sufficient funding so that the goal can be met. Once the restoration begins the length of restoring the site will be about 15-20years. This does not guarantee the rise of population of the native songbirds, but it will overall restore and create a healthy habitat for many species.

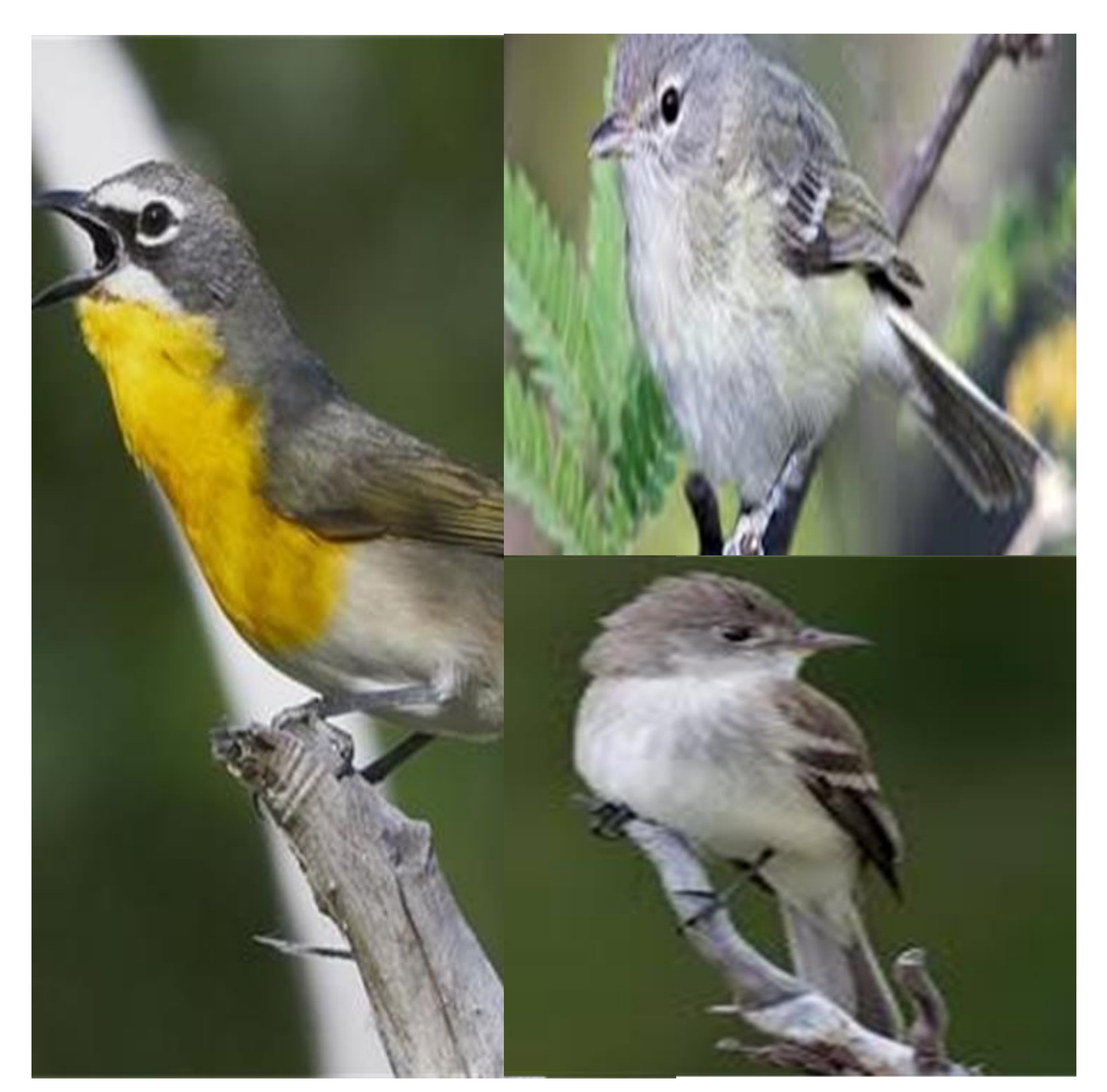

The yellow breasted chat (left) Bells vireo (top right) Willow flycatcher (bottom right) 